\title{
A Review Of The Evaluation Methods Of The Value Of Human Capital Of The Manager In China
}

\author{
Zhao Xian, Central China University of Science and Technology, China \\ Joy L. Colwell, Purdue University Calumet, USA \\ Jing Ma, Purdue University Calumet, USA
}

\begin{abstract}
Recent directives of the Chinese government specify property rights and income distribution for factors of production. The study as to how these factors are allotted appropriate shares of business income is becoming essential to the establishment of the China's modern enterprise system. When the manager is regarded as one of the factors of production, how one measures the value-added becomes a component of the income distribution system of the business. This paper surveys traditional views of the manager as a human capital, and offers an alternative suggestion for the measurement of the human capital of the manager which can more accurately reflect the reality of the operation of the business.
\end{abstract}

Keywords: Chinese enterprise system, factors of production, enterprise manager, human capital valuation methods

\section{INTRODUCTION}

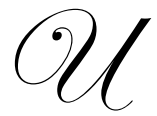

nder the directives of the Chinese government, the property rights of enterprises should be specified and the enterprises' income should be distributed to the factors of production, based upon those factors' contributions. Thus, the study as to how to determine an appropriate distribution has become a top priority for directing the modern Chinese enterprise system. Management skills are an important factor of production, the contribution of which is playing a more important role in the growth of enterprises. The manager is responsible for many of the important strategic decisions, as well as being directly involved in the daily operation and management of the business.

In the Chinese business environment, managerial skills are of vital importance to the successes of the enterprise. The strategic insight and wisdom of the manager plays an irreplaceable role in the operation of the business. It not only creates value for the enterprise but also is an invaluable asset of the business. Faced with many problems existing in the Chinese business environment regarding the mechanism of the motivation of managers, it is of significance and practical value to begin a serious study of the practical ways to assess the value of the manager as a factor of production.

\section{DISCUSSION}

What follows is an overview of the traditional methods of evaluating the manager as a factor of production, including cost based methods, compensation based methods, earning based methods, and opportunity cost methods.

\section{A survey of the traditional methods on the evaluation of human resource of the manager}

The manager is the highest level of human capital in a given enterprise. The value of the human resource of the manager is the potential creative working ability shown through the new value created. A rough survey of the evaluation methods of the value of the human capital of the manager shows that there are basically three types of methods for evaluating the contribution of a manager. 


\section{The cost-based evaluation methods}

This collection or type of method deems the costs that the business has incurred in acquiring and developing the human capital of the manager as the value of the human capital of that manager. Included in this type of method are: (1) the historical costs method, (2) the re-acquirement cost method and (3) the opportunity cost method. The cost-based evaluation methods are chiefly for accounting purposes, and may not reflect the essence of the actual value of the human capital of the manager. Baker, one of the founders of the human capital theories, believes that the investment channels for human capital are through formal school education, on-the-job training, medical insurance, and relocation. The cost that the business incurs for acquiring and developing the manager's human capital may only reflect a part of the total costs of acquiring the human capital. These costs are not intended to value that additional value which the manager creates for the enterprise. Therefore, they may not accurately reflect the real value of the human capital of the manager.

There is an argument to be made, however, that if the labor market is competitive and the market in which the firm sells its output is competitive, the cost of acquiring the manager may indeed reflect the firm's perception of value, on the margin.

\section{The compensation-based evaluation methods}

This group of methods bases calculations of value on the assumption that the compensation is the monetary price of labor. It takes the present value of the salary that the business pays to the manager as the value of the human capital of the manager. The future compensation present value method and the adjusted future compensation present value method are two such methodologies.

\section{The future compensation present value method}

In 1997 Baker published the paper entitled "On the Application of the Economic Concept of Human Resources in the Financial Reports in Accounting Review and introduced the "staff future earning" or "compensation present value" model. This method maintains that the value of the human capital of a certain employee is equal to the present value of the future salaries of the employee in the rest of his employment life. The calculation formula is

$$
V=\sum_{t=1}^{T} \frac{I_{(t)}}{(1+r)^{t}}
$$

Where:

$\mathrm{V}=$ the value of the human capital of the employee,

$\mathrm{I}=$ the expected salary of the employee in $t$ year,

$\mathrm{t}=$ the future working years of the employee,

$\mathrm{r}=$ discount rate of earnings, and

$\mathrm{T}=$ the retirement age of the employee.

\section{The adjusted future salary present value method}

In 1964, in a paper entitled "Human Resource Accounting" published at Michigan University, Professor Hermanson introduced a model of calculating the human capital value by using the adjusted present value of the future compensations and introducing an efficiency factor as an adjustment value of the future compensations. He argued that the differences of profitability of organizations mainly stem from the differences of the quality of human capital. Therefore, the present value of the future compensations of the employee should be adjusted by an efficiency coefficient which reflects the difference of profitability between the organization and the industrial average. The efficiency coefficient can be derived from the investment return ratio, which is the ratio of the profitability of a certain organization to the industrial average during a certain period. The calculation of the efficiency coefficient, $\mathrm{x}$, is as follows:

$\chi=\left[5 \mathrm{X}_{\mathrm{F} 0} / \mathrm{X}_{\mathrm{E} 0}+4 \mathrm{X}_{\mathrm{F} 1} / \mathrm{X}_{\mathrm{E} 1}+3 \mathrm{X}_{\mathrm{F} 2} / \mathrm{X}_{\mathrm{E} 2}+2 \mathrm{X}_{\mathrm{F} 3} / \mathrm{X}_{\mathrm{E} 3}+\mathrm{X}_{\mathrm{F} 4} / \mathrm{X}_{\mathrm{E} 4}\right] / 15$ 
where,

$X_{F}=$ the investment return of a business in the present year ( $F$ takes the values from 0 to 4 , which stands for different years) and

$\mathrm{X}_{\mathrm{E}}=$ The investment return of all the businesses in the industry in the present year (E takes the values from 0 to 4 , which stands for different years).

The value of human capital is then calculated as present value of the future compensations multiplied by the efficiency coefficient, $\chi$.

The salary-based calculation method relies on calculating investment returns, which in turn, partially determine the present value of the compensation of the manager. However the salary that the business pays to the manager is taken as the substitute for the human capital value, which is not entirely convincing. The monetary compensation of the manager not only includes the salary, but also bonuses, dividends and even stock options. As these latter sources are becoming increasingly important components of compensation schemes, base salaries are becoming a less accurate measurement of value.

It might however, be an indication of the lower boundary of value, to use salary plus an estimation of other elements of total compensation, such as bonuses, dividends and stock options.

\section{The earning-based calculation methods}

These methods take the present value of the future earnings that the manager brings to the business as the value of the human capital of the manager, and include (1) the "opportunity value" method and (2) the "earning present value" method.

\section{The opportunity value method}

The opportunity value method refers to the free cash flow to calculate the present value of the human capital of the manager. The method assumes that the human capital of the manager is the key driving factor in the creation of value for the business. As such, this method defines the value of human capital as the difference between the values of the business calculated from free cash flows under the conditions of presence and absence of the specific human capital (Damodaran, 1998). If (i) the human capital of the manager brings continuing, stable free cash flow growth, (ii) the human capital of the manager can span a long enough period; and (iii) a similar qualified successor is fostered by him, then the value of the human capital of the manager can be calculated as:

$$
\mathrm{V}_{\text {人力资本 }}=\Delta V_{\text {企业价值 }}=\frac{F C F_{0}^{*}\left(1+\mathrm{g}^{*}\right)}{\mathrm{r}-\mathrm{g}^{*}}-\frac{F C F_{0}(1+\mathrm{g})}{\mathrm{r}-\mathrm{g}}
$$

where,

$\mathrm{FCF}=$ the free cash flow of the enterprise,

$\mathrm{g}=$ the stable growth of the free cash flow of the enterprise, and

$\mathrm{r}=$ discount rate.

The items with the symbol "*" in the formula are the financial indicators when the human capital of the manager stays in the business.

The merits of this model are that it highlights the key role and irreplaceability of the manager in the business, and emphasizes the use of free cash flow to calculate the value of the human capital of the manager. However, due to the fact that there are difficulties in the measurement of the variables of the model, this model lacks practical applicability. First, free cash flow is a comprehensive concept and includes free cash flow of stocks and free cash flow of the corporation. The free cash flow is a figure adjusted on the basis of the performance of the 
business. If the information on the performance of the business is not based on facts, or if the business makes unrealistic forecasts of its future performance, it impossible to calculate the value of the human capital of the manager with the false free cash flow. Second, this model generally assumes that the growth of the free cash flow of the business is stable or steady, which is not likely the case. The performance of the business fluctuates implying that free cash is neither constant nor growing steadily. Third, the free cash flow of the business does not result solely from the contribution of the human capital of the manager; human capital of employees and financial capital contribute, too.

\section{The earning present value method}

The value of the human capital of the manager is a realization of value through the integration of the human capital and the other factors of productions and is closely related to the performance of the business. Therefore, when one evaluates the value of the manager, the present value of the earnings should be considered. The earning present value method is an evaluation method that converts the earnings of assets to the value of assets. The evaluation of the value of the manager by the earning present value method is placing the manager into a given business and taking the series of future earnings that the manager can create for the business during the expected time period of her or his stay at the organization as the basis on which the value of the manager is measured. A contribution percentage is introduced to designate the value of contribution of the manager to the business. The evaluation mode is as follows:

$$
P=\beta \times \sum_{t=1}^{n} F_{t}(1+i)^{-t}
$$

In this model,

$\mathrm{p}=$ the evaluated value of the human capital of the manager,

$\beta=$ the contribution percentage, i.e., the degree of contribution of the manager to the business,

$\mathrm{F}_{\mathrm{t}}=$ expected earnings for year $\mathrm{t}$,

$\mathrm{i}=$ discount rate, and

$\mathrm{n}=$ the working life of the manager at this business.

Taking full consideration of the characteristics of the human capital of the manager and making use of the theory of distribution for factors of production, the earning present value method tries to isolate the contribution of the manager, $\beta$, to the business from total output on the basis of the evaluation of the overall profitability. However, it is not good for this model to use profit as the sole measure of the performance of the business, for the model not only does not consider the deduction of costs but also ignores the value of the intangible assets, such as brand, that the manager has added during the period of her stay at the business.

\section{THE AUTHORS' VIEWPOINT}

In the corporate governance of the modern enterprise, the relationship between the stock holders and the managers is a relationship of trust. The stockholders contribute the material capital and the manager contributes the human capital; and the combination of the material capital and human capital promote the increase of the value of the business. Thus the enterprise can be considered as a contract between the stockholder and the manager. Similar to the role of the material capital, the human capital of the manager contributes to the creation of value for the business and the sharing of risks.

The business can be considered as a contract for the addition of value. The realization of added value comes from the cooperation of the human capital of the manager and the material capital of the contributor. The business has the three characteristics: transaction, production and value addition. The value of the human capital of the manager is embodied in the three characteristics. From the perspective of transaction, any owner of a single factor of production cannot start the operation; the operation of the business is made possible only when the single factor of production of the owner is combined with the other factors of production. The essential purpose of the operation of the business is to sell the tangible or intangible products at a price exceeding cost so as to realize the addition of value to the original capital. The prerequisite for the addition of value is the free exchange of factors of production so as to make the combination of material capital and human capital possible. The manager, through such 
various types of work as resources allocation, management and decision-making, organizes the formerly discrete material capital so as to change the "original-use" value of the materials (the value transfer process) and creates the "new-use" value (the value addition process). The human capital of the manager is the condition and means for the transfer of value and addition of value. Therefore, this paper maintains that the evaluation of the value of the manager must be based on the process of value addition to the business.

A practical method is proposed in this paper to evaluate the value of the human capital of the manager. Economic Value Added, or EVA, is taken as a basic indicator of the added value of the business. First, the EVA value is divided between the financial capital and the human capital. The latter includes both the value of the ordinary labor and the value of the manager. Then, the human capital is divided between the human capital of the manager and the human capital of the ordinary laborer, thus the human capital of the manager is decided.

One important consideration is the type of on-the-job training (OJT) a manager will experience and the mix has implications on how the manager's compensation profile (over time) reflects EVA. In labor economics literature, we identify "firm-general" and "firm specific" OJT. Firm-specific training would increase the manager's productivity and value only for the firm. In other words, if the manager left the firm, the skills acquired have no value with another firm. In this case, the firm would be expected to compensate the manager for the training period by paying above value compensation early in the career as an investment. If the type of training the manager receives is firm-general, the manager carries the new-found skills to any other firm. In this case, the manager would receive less than value compensation early in her career, as the investment is in the manager herself.

\section{CREATION OF A MODEL}

The thread of thinking in the creation of the model is to take the characteristics of the human capital of the manager and the role of the human capital of the manager in the process of value creation as the focal points. The following points are also considered in the construction of the model:

1) since the contribution of the manager varies from industry to industry, an industry weighed value factor is introduced;

2) based on the standard of the present value of the future EVA, the expected EVA produced by the business is taken as a basis and the discount rate is considered.

3) the percentage of the contribution of the human capital to EVA is introduced to decide on the actual contribution of the human capital;

4) the value of the human capital of the manager is arrived at by subtracting the contribution of ordinary human capital from the contributions of general human capital.

The basic model for the evaluation of the value of the human capital of the manager is as follows:

$P=\alpha \times \beta \times \sum_{t=1}^{n} E V A_{t}(1+i)^{-t}$

In this formula,

$\mathrm{P}=$ the evaluated value of the human capital of the manager,

$\alpha=$ industrial weight factor,

$\beta=$ percentage of contribution, i.e., the degree of human capital to the operational performance of the business;

$\mathrm{EVA}_{\mathrm{t}}=$ expected economic value addition for year $\mathrm{t}$,

$\mathrm{i}=$ discount rate, and

$\mathrm{n}=$ the working years of the manager.

Let us define $\beta$ as $\mathrm{H}-\mathrm{h}$, where

$\mathrm{H}=$ value of all human capital

$\mathrm{h}=$ the percentage of contribution of the ordinary human capital.

The difficulty here is the determination of $\beta$, or $\mathrm{H}$ and $\mathrm{h}$. 
Assume the firm's production function of output, Q, is given by the Cobb-Douglas production function as follows:

$Q=A L^{\alpha} K^{\beta}$

where:

$\mathrm{L}=$ the input of human capital,

$\mathrm{K}=$ the input of material input, and

$\mathrm{A}, \alpha$, and $\beta$ are all parameters to be estimated.

From the relationship $Q=A L^{\alpha} K^{\beta}$, the marginal products of the factors $\mathrm{L}$ and $\mathrm{K}$ are

$$
M P_{L}=\partial Q / \partial L=A \alpha L^{\alpha-1} K^{\beta}
$$

and

$$
M P_{K}=\partial Q / \partial K=A \beta L^{\alpha} K^{\beta-1}
$$

Also because of $\frac{L \cdot M P_{L}}{K \cdot M P_{K}}=\frac{L \cdot \partial Q / \partial L}{K \cdot \partial Q / \partial K}=\frac{L \cdot A \alpha L^{\alpha-1} K^{\beta}}{K \cdot A \beta L^{\alpha} K^{\beta-1}}=\frac{\alpha}{\beta}$

it's easy to see that $H=\frac{L \cdot M P_{L}}{L \cdot M P_{L}+K \cdot M P_{K}}=\frac{\alpha}{\alpha+\beta}$

\section{Determination of $h$}

$\mathrm{h}$ is the ratio of the human resource cost of normal labor to the total human resource cost. For the determination of $\mathrm{h}$, we also can refer to the Cobb-Douglas function. But now we assume that the input of material resources is fixed, and the input of normal labors is L1, and the rest input is L2 (in this article, it is ploughed into by the entrepreneur). So we can educe a new input and output function under this assumption:

$$
Q=A\left(L_{1}+L_{2}\right)^{\alpha} \bar{K}^{\beta}
$$

We know:

$$
\begin{aligned}
& M P_{L_{1}}=\partial Q / \partial L_{1}=A \alpha\left(L_{1}+L_{2}\right)^{\alpha-1} \bar{K}^{\beta} \\
& M P_{L_{2}}=\partial Q / \partial L_{2}=A \alpha\left(L_{1}+L_{2}\right)^{\alpha-1} \bar{K}^{\beta}
\end{aligned}
$$

And because $\frac{L_{1} \cdot M P_{L_{1}}}{L_{2} \cdot M P_{L_{2}}}=\frac{L_{1} \cdot \partial Q / \partial L_{1}}{L_{2} \cdot \partial Q / \partial L_{2}}=\frac{L_{1} \cdot A \alpha\left(L_{1}+L_{2}\right)^{\alpha-1} \bar{K}^{\beta}}{L_{2} \cdot A \alpha\left(L_{1}+L_{2}\right)^{\alpha-1} \bar{K}^{\beta}}=\frac{L_{1}}{L_{2}}$ 
It follows that: $h=\frac{L_{1} \cdot M P_{L_{1}}}{L_{1} \cdot M P_{L_{1}}+L_{2} \cdot M P_{L_{2}}}=\frac{L_{1}}{L_{1}+L_{2}}$

I think it can be solved by hierarchy analysis method. Because the data is currently being collected, this topic will be the subject of further discussion in a future paper.

The Cobb-Douglas function is rarely used anymore, due to its restrictive assumptions in regards to the firm's elasticity of substitution between inputs. This elasticity captures the degree to which the firm can substitute one factor of production, such as the manager, for another, such as hourly labor or capital, as the factor price of one changes. The Cobb-Douglas function restricts this elasticity to a value of 1 . A slightly more sophisticated version is the Constant Elasticity of Substitution, or CES, function. While the elasticity of substitution is still constant, it is not restricted to a value of 1 . Flexible functional forms, often called "translog" or "translogrithmic" functions place no restrictions on the elasticity of substitution or shares.

There are advantages to the use of EVA to evaluate the value of the business. As EVA is a more accurate reflection of the operational performance of the business, the evaluation of the value of the manager based on EVA can reflect the reality more accurately. The consideration of the costs of the equity capital is the most unique and important aspect of the evaluation method based on EVA. Only when the performance of equity capital cost is considered can the real profitability of the business be reflected. Those businesses that cannot generate enough profits to compensate for the opportunity cost of the equity capital are actually reducing the wealth of the stockholders. Only when the income of a business exceeds the costs of all the capitals of the business can we say that the manager adds value to the business and creates wealth for stockholders. The EVA theory also points out clearly that the manager of the business must consider the returns of investment of all forms of capital. Through the consideration of the opportunity costs of all form of capital, EVA shows the amounts of wealth of the stockholders that a business creates or loses in a fiscal year.

In order to examine the rationality and dependability of the proposed model determining manpower capital value of the entrepreneur, this research has used a real example, checking computations tentatively in one enterprise (A Company). The proposed model should predict the EVA (Economic Value Added) of Company A in the following five years.

\section{SAMPLE ANALYSIS USING PROPOSED MODEL}

Using the proposed EVA (Economic Value Added) model to determine the enterprise manager's (entrepreneur's) value, we make the following assumptions. The entrepreneur's term of office was five years: the authors suppose that the term of office is the alloted time of management, and do not consider probability of leaving before the end of the five year term.

\section{Determination of EVA.}

We should be able to predict the EVA in the following five years according to the past Achievement. The table following is EVA (Economic Value Added) of Company A from 2002 to 2006.

Table 1: The economic value added (EVA) of Company A from 2002 to 2006

\begin{tabular}{|c|c|c|c|c|c|}
\hline year & 2002 & 2003 & 2004 & 2005 & 2006 \\
\hline EVA(ten thousand yuan) & 5382 & 9814 & 13968 & 16880 & 22133 \\
\hline
\end{tabular}

Source of the materials: A Company's financial data analysis

Below is a chart showing the trend in Company A's performance over the five year period of 2002-2006. 
Chart 1. Company A's EVA growth over previous five years

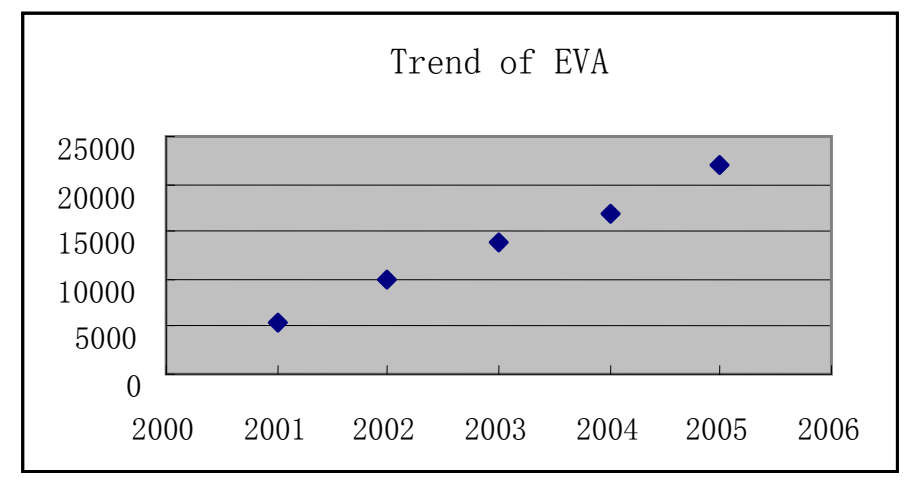

This Company's EVA shows a linear increasing trend: based on this, we adopt the level and exponential function to predict the EVA of following five years:

$$
\begin{aligned}
\sum_{t=1}^{5} E V A_{t}(1+i)^{-t} \\
=E V A_{1}(1+i)^{-1}+E V A_{2}(1+i)^{-2}+E V A_{3}(1+i)^{-3}+E V A_{4}(1+i)^{-4}+E V A_{5}(1+i)^{-5} \\
=\frac{22111.91}{(1+10.27 \%)}+\frac{31794.71}{(1+10.27)^{2}}+\frac{36636.11}{(1+10.27 \%)^{3}}+\frac{41477.51}{(1+10.27 \%)^{4}}+\frac{46318.9}{(1+10.27 \%)^{5}} \\
=129987.4 \text { 万元 }
\end{aligned}
$$

\section{Determination of $\beta$ (value of contribution of human capital)}

Every index of Company A from 2004 to 2006 is seen in the following Table 2. Among them the material capital is the weighted average of initial investing value and net value of the fixed assets, the human capital is all salary, welfare funds and expenditures concerning human capital.

Table 2 Output against input of human capital and material (Unit ten thousand Yuan)

\begin{tabular}{|l|c|c|c|}
\hline & Output Q & material capital input K & human capital input L \\
\hline 2004 & 2680395.48 & 6151551.639 & 463853.8982 \\
\hline 2005 & 3062416.62 & 12540386.41 & 496145.6972 \\
\hline 2006 & 3535180.47 & 19055282.3 & 555845.0832 \\
\hline
\end{tabular}

Bring the data of three years into $Q=A L^{\alpha} K^{\beta}$, and solve the equation group, we can know $\alpha=0.8812, \beta=0.1237$. Thus we can calculate out $H=\frac{\alpha}{\alpha+\beta}=0.876=87.6 \%$. We also can get the following data: Among them the input of ordinary human capital is all salary welfare funds and other expenditures concerning ordinary human capital, where the input of Human Capital of the Manager is that the total input of human capital minus the ordinary human capital input. 
Table 3 Input of ordinary human and Manager's Human Capital

Unit: ten thousand Yuan

\begin{tabular}{|l|c|c|c|}
\hline & Total input of human capital $\mathbf{L}$ & Input of ordinary human capital $\mathbf{L}_{\mathbf{1}}$ & input of Human Capital of the Manager $\mathbf{L}_{\mathbf{2}}$ \\
\hline 2004 & 463853.898 & 354697.728 & 109156.1702 \\
\hline 2005 & 496145.697 & 388001.988 & 108143.7092 \\
\hline 2006 & 555845.083 & 452891.558 & 102953.5252 \\
\hline
\end{tabular}

Bring data to $h=\frac{L_{1}}{L_{1}+L_{2}}$ Calculate and fetch the average result $h=0.7872=78.72 \%$.

So $\beta=H \times(1-h)=0.876 \times(1-0.7872)=0.1864=18.64 \%$

\section{Determination of $\alpha$}

Industrial weight factor $\alpha$ is synthesized and evaluated according to the real state of national economic development by the expert panel. Considering that Company A belongs to ordinary industry, $\alpha$ can be in medium level. The authors think 0.52 is rational.

\section{Determination of $\mathbf{P}$}

$$
P=\alpha \times \beta \times \sum_{t=1}^{n} E V A_{t}(1+i)^{-t}
$$

$=0.5218 .64 \% 129987.4$

$=125,994,200$

When tested by the above-mentioned examples, the model based on EVA for the evaluation of the value of manager's human capital which this paper proposes has feasibility, and the evaluation process is easy to operate.

\section{CONCLUSION}

There are advantages to the use of EVA to evaluate the value of the business. As EVA is a more accurate reflection of the operational performance of the business, the evaluation of the value of the manager based on EVA can reflect reality more accurately. The consideration of the costs of equity capital is the most unique and important aspect of the evaluation method based on EVA. Only when the performance of equity capital cost is considered can the real profitability of the business be reflected. Those businesses that cannot generate enough profits to compensate for the opportunity cost of the equity capital are actually reducing the wealth of the stockholders. Only when the income of a business exceeds the costs of all the capitals of the business can we say that the manager adds value to the business and creates wealth for stockholders. The EVA theory also points out clearly that the manager of the business must consider the returns of investment of all forms of capital. Through the consideration of the opportunity costs of all form of capital, EVA shows the amounts of wealth of the stockholders that a business creates or loses in a fiscal year.

Overall, some advantages of the EVA approach are as follows:

1. EVA will link the stockholder's wealth with the decision-making of the business, which will solve the issue of the trust relationship between the stockholder and the manager.

The adoption of the indicator EVA is helpful to let the manager incorporate the main financial indicator - the maximization of the stockholder's wealth - in the process of decision-making in the operation of the 
business. The value of the business depends on whether the investors' expected future profits exceed the total cost of capital. The continuous growth of the EVA of a business means the continuous growth of the market value of the business and the steady growth of the wealth of stockholders. Therefore, the application of EVA will help the business to make decisions in the interest of the stockholders. For example, a business can use the EVA indicator to provide a correct evaluation standard to allocate funds among different business divisions; whereas the uses of such indicators as financial profits and return on investment may lead to imbalanced allocation of capital resources, for the former leads to over-capitalization and the latter leads to under-capitalization.

2. The use of EVA based method stresses the sustainable development of the business and tempers the nearsightedness of the manager.

The EVA based method focuses on the long term development of the business, for it does not encourages the overstatement of the short term effect at the expense of long term performance; instead, it encourages the manager to make the investment decisions that can bring long term profits to the business, such as the research and development of new products, the training of human resources, etc. As a result, the application of the EVA based method will meet not only the long term interest of development of the business but also the requirement of the new economy, for the new economy the knowledge-based intangible assets will become the decisive driving force of the future cash flow and market value of the business.

3. The EVA based method reflects a new view of the value of the business, which will motivate the manager to work harder to grow the value of the business

The improvement of EVA is closely linked with the increase of the value of the business. To increase the market value of the company, the return on the capital of the business managed by the manager must exceed the return on the capital provided by investments of the same risk conditions, so that the contributions of the investors can generate the added value, and the investors will increase their investment and other potential investors will be enticed to put their funds into this business, which eventually will lead to the rise of the prices of the stock of the business and the market value of the business.

4. The EVA based method reflects the ability of future development, which encourages the manager to focus on the development of the business.

Stern Steward Company claimed that in the field of the evaluation of the values of the high-tech companies, through the studies of the capitalization of R\&D expenses and marketing and advertising expenses, it shows that the indicator EVA is more advantageous over other indicators. Many high-tech companies spend huge amounts of funds on R\&D, marketing and advertising expenses. The EVA method will more likely capitalize theses expenditures, which means that theses expenditures are treated as investments that require returns, not as expenses. This is because the intangible assets plays a very important role in the sustainable development of the company. The capitalization of expenses makes EVA especially advantageous over other methods in the evaluation of the value of the high-tech companies.

In view of the above analysis, we can draw the conclusion that the EVA model overcomes the flaws of the evaluations using the traditional performance indicators and accurately reflects the value that the manager creates for the company in a given period. Moreover, The EVA indicator can be acquired from the financial data of the balance sheet and the income statement with some accounting adjustments, thus providing the basic data for the calculation of the value of the human capital of the manager. Therefore, the use of the EVA as a base to calculate the value of the human capital of the manager is a reasonable choice.

\section{AUTHOR INFORMATION}

Zhao Xian, doctoral student at Central China University of Science and Technology, Associate Professor of Inner Mongolia University of Science and Technology, Visiting Researcher at Purdue University Calumet, 2008-09.

Joy L. Colwell, J.D., is an Associate Professor of Organizational Leadership and Supervision and Assistant Dean for Graduate Studies in the School of Technology at Purdue University Calumet. She teaches courses in such areas as conflict management and leadership and ethics, as well as courses on legal issues in the employment relationship. 
One of her primary areas of scholarship involves professional skills in technical professions. Professor Colwell received her training in civil and family mediation in the early 1990s, and continues to train professionals in civil mediation skills. She also has extensive experience with distance education.

Jing Ma, junior Honors student in the School of Management at Purdue University Calumet, Hammond, Indiana, majoring in Finance and Accounting. She is also president of Students' Research and Development Association.

\section{REFERENCES}

1. See Baker, George P., Jensen, Michael C., and Murphy, Kevin J., Compensation and Incentives: Practice v. Theory, The Journal of Finance, Vol. XLIII, No. 3, 1988 and Baker, "On the Application of the Economic Concept of Human Resources in the Financial Reports in Accounting Review, 1997

2. See Roger H. Hermanson, Accounting for Human Assets, Occasional Paper No. 14 (East Lansing; Bureau of Business and Economic Research, Graduate School of Business Administration, Michigan State University, 1964)

3. See Aswath Damodaran, Investment Valuation (Second Edition) John Wiley \& Sons, New York (2004) and Valuation Approaches and Metrics: A Survey of the Theory and Evidence, Stern School of Business November 2006. http://pages.stern.nyu.edu/ adamodar/

4. Duan, Xingmin et Zhang, Zhihong, Study on Evaluation of the Human Capital in China, Xian: Xian University Press, 2006.

5. Zhu Xiumin et Wu Zhongchun, "In inquiry into the methods of calculation of the human capital", Journal of Central University of Finance and Economics, 2005(12)

6. Li shicong et Xia Fei, "The theory and methods on the present value of the human resources", Business management , 2002(3)

7. Du Xingqiang et Huang Liangwen, "A study of the calculation model of the value of human capital of the manager", Industrial Economy in China, 2003(8)

8. Gu Qinxuan, The Value and Income distribution of The Mangers of The State-owned Enterprisers, Shanghai: Each China University of Science and Technology Press, 2004.

9. Ma Ningli et Wang Jining, "A study of the mathematical model and methods of the evaluation of the value of the business", Modern Management Science, 2004 (5).

10. Wang Haijie et Zhang Xizhen, "The unique characteristics of the human capital of the manager and innovations on its modes of governance", Studies on Economic Issues, 2004(5)

11. Li Zhongmin, Human Capital: A Theoretical Framework and Its Explanations to Some Issues in China, Beijing: Economics Science Press, 1999. 
NOTES 